\title{
Proposal of a Maturity Model for Supply Chain Sustainability
}

\author{
Elisabete M. F. Correia ${ }^{1}$, Susana G. Azevedo ${ }^{2, *}$ and Helena Carvalho ${ }^{3}$ \\ ${ }^{1}$ ISCAC - Instituto Politecnico de Coimbra, Portugal \\ ${ }^{2}$ CEFAGE-UBI, UNIDEMI, Department of business and Economic, University of Beira Interior, Portugal \\ ${ }^{3}$ UNIDEMI, Faculty of Science and Technology, FCT, Universidade Nova de Lisboa \\ ${ }^{*}$ Corresponding author
}

\begin{abstract}
This paper proposes a Maturity Model (MM) to assess the level of sustainability of Supply Chains. To reach the integrated Maturity Model an hierarchical and partitioned perspective is adopted by sustainability practices, sustainability dimensions and by SC. A simulation study is performed to illustrate the application of the proposed maturity model and its potentialities.
\end{abstract}

Keywords-component; maturity models, supply chain, sustainability

\section{INTRODUCTION}

Maturity models (MMs) have been widely adopted in various contexts such as risk management, new product development and human resources management, process management, and supply chain management (SCM), among others [1]. The MMs are also deployed in topics related to sustainability such as the eco-design [2] and corporate sustainability [3]. The use of MMs has been considered a valuable tool for supply chains (SCs) diagnosis and operations improvement [4] since they could help companies to assess the initial state and progress of their sustainability behaviour [5]. The attention and increasing concerns on sustainability by business and societal stakeholders have created pressures on companies to provide not only economic benefits but also to address environmental and social concerns, also known as triple bottom line (TBL) [6]. Despite the topic relevancy there are few quantities of researches on SC sustainability focusing simultaneously the TBL perspective and there are also few studies linking SC, sustainability and MMs. So, this paper presents an innovative topic in suggesting a MM for assessing and monitoring the level of sustainability of the SC.

\section{THEORETICAL BACKGROUND}

The sustainability of SC has been identified as a key sustainable development component [7] and a way to achieve improvements, particularly in the logistics performance level and in the use of resources e.g. [8], [9]. To achieve better levels of sustainability some SCM practices have to be changed and managed in a different way [10]. The process of incorporating sustainability in SCM context is not trivial since it involves greater complexity in the management of resources and flows and requires more accurate decision making at various levels [11]. In addition, the requirements of all stakeholders to become the SC more sustainable from the short to the long-term perspective, demands the use of more suitable frameworks to deal with those complexities [11]. The MMs allow describing the evolution of a specific system over time and when applied to SC sustainability seem to be a useful tool for analysis and evaluation assessment. It is further considered that monitoring/evaluation is fundamental to incorporate sustainability in SC not only to communicate performance to internal stakeholders and the market, but to chart improvement trajectories [10]. The SC sustainability MMs have been presented as: (1) a descriptive instrument for assessing strengths and weaknesses [12]; (2) a roadmap for performance improvement [4]; (3) a comparative tool to evaluate the processes / company and compare them with standards and best practices of other organizations [13], thus allowing the internal and external benchmarking [14].

The objective of this paper is to propose a Supply Chain Maturity Model (SCMM) to assess the level of sustainability by considering three integrative perspectives: (1) sustainability practice, (2) of sustainability dimension, i.e. economic, social and environmental, (3) SC level.

\section{CONCEPTUAL Model: MATURITY MODEL FOR THE SUPPLY CHAIN SUSTAINABILITY}

The rational supporting the proposed SSCMM considers that each dimension of sustainability $(j=1$, economic; $j=2$, social; $j=3$, environmental) is formed by a set of sustainability practices with different levels of implementation $\left(\mathrm{P}_{\mathrm{ji}}\right)$. For each sustainability dimension a maturity model level is computed (sustainable dimension maturity model - SDMM) considering the level of implementation of all practices associated to it.

Once assessed the level of sustainability for each dimension of sustainability the SSCMM is computed considering the levels of maturity in each dimension of sustainability and aggregating them in order to get different levels of maturity for SC sustainability.

The proposed maturity model is illustrated in Figure 1.

To attain the maturity model for sustainability practices (PMM) the identification of the sustainability practices associated to each dimension of sustainability is mandatory. This represents the first step in the approach suggested in this study (Table 1 ). 


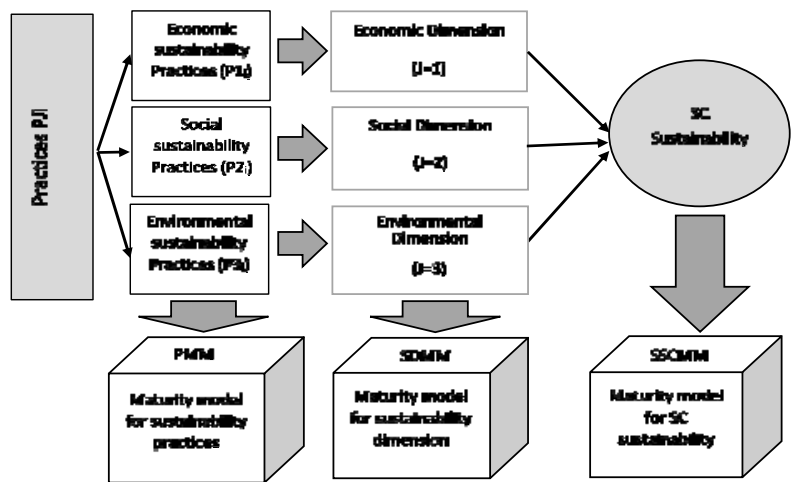

FIGURE I. CONCEPTUAL MODEL FOR ASSESSING THE MATURITY MODEL OF SUPPLY CHAIN SUSTAINABILITY

TABLE I. SUSTAINABILITY PRACTICES

\begin{tabular}{|l|l|}
\hline \multicolumn{1}{|c|}{ Sustainability dimension } & \multicolumn{1}{c|}{ Practices } \\
\hline Economic $j=1$ & $\mathrm{P}_{1 i}$ with $i=1 \ldots \mathrm{n}$ \\
\hline Social $j=2$ & $\mathrm{P}_{2 i}$ with $i=1 \ldots \mathrm{n}$ \\
\hline Environmental $j=3$ & $\mathrm{P}_{3 i}$ with $i=1 \ldots \mathrm{n}$ \\
\hline
\end{tabular}

The selection of the sustainability practices associated to each sustainability dimension will be performed according to the literature review and using also the Delphi technique. The literature review is used to identify a set of practices in each sustainability dimension and the Delphi technique will make possible to reduce the amount of practices previously selected to the ones considered as the most important by the professionals from the industry. The choice of the Delphi technique was supported by [15] and [16]. According to these authors, one clear use of the Delphi method is when the issue under investigation does not lend itself to precise analytical techniques, but can benefit greatly from subjective judgments on a collective basis. This is what happens with the selection of the practices to be considered in each of the sustainability dimensions.

Once identified the practices considered in each sustainability dimension the next step consists in computing the level of maturity of each sustainability practice i for the dimension of sustainability $\mathrm{j}\left(\mathrm{LMP}_{\mathrm{ij}}\right)$ (Equation 1).

$$
\left(\mathrm{LMP}_{i j}\right)=\left(\Sigma \mathrm{P}_{i j}\right) / \mathrm{n}
$$

where,

$\mathrm{LMP}_{i}$-level of maturity for practice $i$

$\mathrm{P}_{j i}$ - implementation level of practice $i$ for the dimension of sustainability $j$. The level of implementation of each practice is registered in a 5-point likert scale.

$n$ - number of companies that makes part of the SC.

Attending to Equation 1, the criteria used to identify the different levels of maturity for each sustainability practice is the following:

Level of Maturity $=1$, if $1 \leq L M P_{i j}<2$

Level of Maturity $=2$, if $2 \leq L M P_{i j}<3$

Level of Maturity $=3$, if $3 \leq L M P_{i j}<4$
Level of Maturity $=4$, if $4 \leq L M P_{i j}<5$

Level of Maturity $=5$, if $L M P_{i j}=5$

After obtained the maturity model by sustainability practice it is now possible to compute the level of maturity by sustainability dimension j $\left(\mathrm{LMSD}_{\mathrm{j}}\right)$ using Equation 2.

$$
\mathrm{LMSD}_{j}=\left(\Sigma \mathrm{P}_{j i}\right) / \mathrm{m}_{i j} \times \mathrm{n}
$$

where,

$\mathrm{LMSD}_{j}$ - level of maturity by sustainability dimension $j$.

$\mathrm{P}_{j i}$ - implementation level of practice $i$ for the dimension of sustainability $j$.

$\mathrm{m}_{i j}$ - number of practices $i$ associated to the dimension of sustainability $j$.

$\mathrm{n}$-number of companies that makes part of the supply chain.

Using the Equation 2, the criteria used to identify the different levels of maturity by sustainability dimension is the following:

Level of Maturity $=1$, if $1 \leq L M S D_{j}<2$

Level of Maturity $=2$, if $2 \leq L M S D_{j}<3$

Level of Maturity $=3$, if $3 \leq L M S D_{j}<4$

Level of Maturity $=4$, if $4 \leq L M S D_{j}<5$

Level of Maturity $=5$, if $L M S D_{j}=5$

Finally, the maturity model for SC sustainability is computed aggregating the level of maturity of each dimension of sustainability. That is, the level of maturity for the SC sustainability is computed by using the Equation 3:

$$
\mathrm{LM}_{S C}=\Sigma\left(\mathrm{LMSD}_{j}\right) / \mathrm{q}
$$

where,

$\mathrm{LM}_{S C}$ - level of maturity of the SC.

$\mathrm{LMSD}_{j}-$ level of maturity for sustainability dimension $j$.

$\mathrm{q}$ - number of dimensions of sustainability, e.g. $\mathrm{q}=3$.

Attending to Equation 3, the criteria that makes possible identify the level of the maturity for the SC as regards the sustainability are:

$$
\begin{aligned}
& \text { Level of Maturity }=1, \text { if } 1 \leq L M_{S C}<2 \\
& \text { Level of Maturity }=2 \text {, if } 2 \leq L M_{S C}<3 \\
& \text { Level of Maturity }=3 \text {, if } 3 \leq L M_{S C}<4 \\
& \text { Level of Maturity }=4 \text {, if } 4 \leq L M_{S C}<5 \\
& \text { Level of Maturity }=5 \text {, if } L M_{S C}=5
\end{aligned}
$$

\section{SiMULATION STUDY}

To illustrate the application of the proposed methodology a simulation study is performed. The suggested scenario is the following: Considering a SC formed by ten companies. Each dimension of sustainability is associated with different number of practices $\left(\mathrm{P}_{j i}\right)$. The economic dimension is formed by 5 practices, the social by 4 and the environmental by 6 practices. The practices implementation level is illustrated in Table 2. 
TABLE II. IMPLEMENTATION LEVEL OF PRACTICES

\begin{tabular}{|c|c|c|c|c|c|c|c|c|c|c|c|c|}
\hline & \multicolumn{10}{|c|}{ Company } \\
\hline & & & C1 & C2 & C3 & C4 & C5 & C6 & C7 & C8 & C9 & C10 \\
\hline \multirow{15}{*}{$\underbrace{0}_{\tilde{0}}$} & \multirow{5}{*}{ 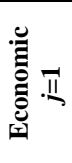 } & $\mathbf{P}_{11}$ & 1 & 1 & 2 & 1 & 1 & 3 & 1 & 2 & 2 & 1 \\
\hline & & $\mathbf{P}_{12}$ & 2 & 2 & 3 & 5 & 2 & 3 & 1 & 3 & 5 & 2 \\
\hline & & $\mathbf{P}_{13}$ & 2 & 4 & 5 & 4 & 1 & 2 & 1 & 5 & 4 & 3 \\
\hline & & $\mathbf{P}_{14}$ & 4 & 5 & 4 & 3 & 4 & 2 & 4 & 4 & 3 & 5 \\
\hline & & $\mathbf{P}_{15}$ & 4 & 5 & 3 & 5 & 2 & 5 & 5 & 3 & 5 & 4 \\
\hline & \multirow{4}{*}{ 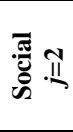 } & $\mathbf{P}_{21}$ & 1 & 2 & 2 & 2 & 3 & 2 & 2 & 1 & 2 & 3 \\
\hline & & $\mathbf{P}_{22}$ & 2 & 2 & 3 & 2 & 2 & 2 & 2 & 3 & 1 & 2 \\
\hline & & $\mathbf{P}_{23}$ & 2 & 2 & 3 & 2 & 2 & 2 & 2 & 3 & 1 & 2 \\
\hline & & $\mathbf{P}_{24}$ & 3 & 3 & 3 & 1 & 2 & 2 & 4 & 2 & 1 & 5 \\
\hline & \multirow{6}{*}{ 冚 } & $\mathbf{P}_{31}$ & 3 & 5 & 4 & 5 & 5 & 4 & 4 & 4 & 5 & 5 \\
\hline & & $\mathbf{P}_{32}$ & 5 & 3 & 5 & 5 & 5 & 4 & 4 & 5 & 5 & 5 \\
\hline & & $\mathbf{P}_{33}$ & 3 & 5 & 5 & 5 & 5 & 3 & 5 & 5 & 5 & 4 \\
\hline & & $\mathbf{P}_{34}$ & 5 & 5 & 5 & 4 & 5 & 3 & 5 & 5 & 4 & 5 \\
\hline & & $\mathbf{P}_{35}$ & 5 & 5 & 4 & 5 & 5 & 5 & 5 & 4 & 5 & 5 \\
\hline & & $\mathbf{P}_{36}$ & 5 & 5 & 4 & 5 & 5 & 3 & 4 & 4 & 5 & 5 \\
\hline
\end{tabular}

After the sustainability practices being identified and the implementation level registered it is now possible to compute the Equation 1, Equation 2 and also Equation 3 in order to assess the levels of maturity for practices $\left(\mathrm{LMP}_{i j}\right)$, by dimension of sustainability $\left(\mathrm{LMSD}_{j}\right)$ and also for the SC (LMSC) (Table 3).

TABLE III. ASSESSMENT OF MATURITY LEVELS

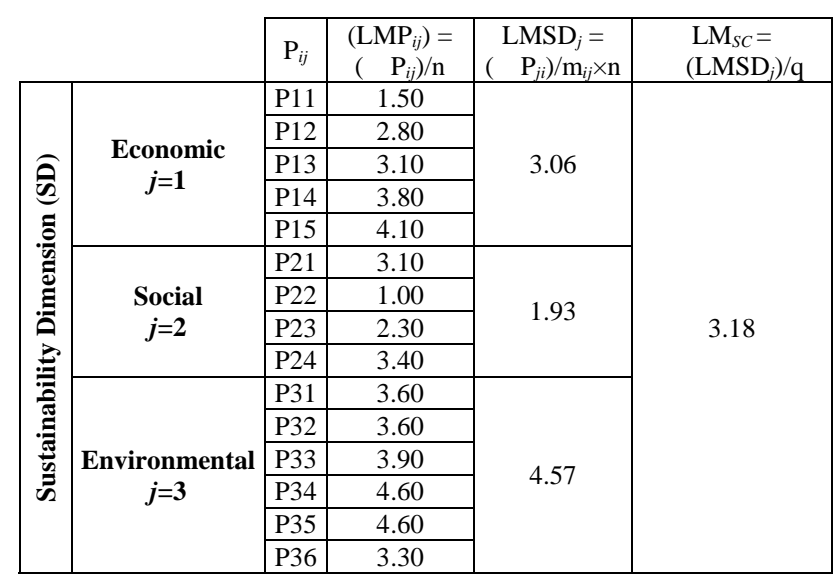

Clustering the practices associated to the different dimensions of sustainability by levels of maturity (Table 4) supports the identification of their state in terms of maturity. This supports managers in their decision making giving insights on the necessity of adopting new measures and policies in order to go on to higher levels of maturity. It also makes possible to illustrate the level of maturity of the sustainability practices by sustainability dimension.

\section{TABLE IV. CLUSTERING SUSTAINABILITY PRACTICES BY LEVEL OF} MATURITY

\begin{tabular}{|c|c|c|c|}
\hline & Economic & Social & Environmental \\
\hline Level of maturity 1 & $\mathrm{P}_{11}$ & $\mathrm{P}_{22}$ & \\
\hline Level of maturity 2 & $\mathrm{P}_{12}$ & $\mathrm{P}_{21}, \mathrm{P}_{23}, \mathrm{P}_{24}$ & \\
\hline Level of maturity 3 & $\mathrm{P}_{13}$ & & \\
\hline Level of maturity 4 & $\mathrm{P}_{14}, \mathrm{P}_{15}$ & & $\mathrm{P}_{31}, \mathrm{P}_{32}, \mathrm{P}_{33}, \mathrm{P}_{34}, \mathrm{P}_{35}, \mathrm{P}_{36}$ \\
\hline Level of maturity 5 & & & \\
\hline
\end{tabular}

Another kind of analysis that can be performed with the proposed approach is to identify the level of maturity of each sustainability dimension (LMSDj). According to both the data computed in Table (3) and the rule of thumb to identify in which level of maturity the sustainability dimensions are it is possible to identify the level of maturity for each sustainability dimension. Being so, as the LMSD1= 3.06 this means that the economic dimension of sustainability is in the level of maturity 3 ; the social dimension is in the level of maturity 1 (LMSD2 $=1.93$ ) and the environmental dimension of sustainability is in the level of maturity 4 (LMSD3). These results can be illustrated in Figure 2.

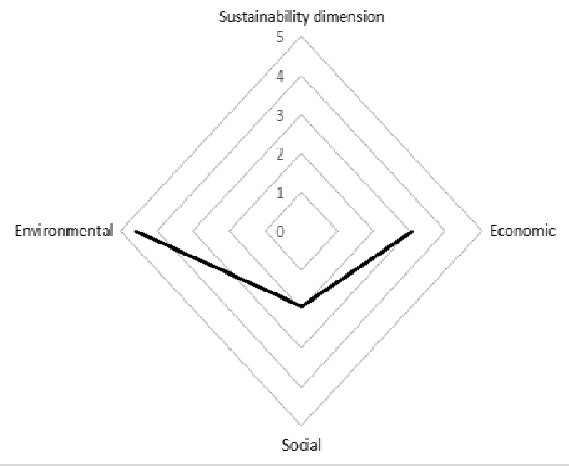

FIGURE II. LEVEL OF MATURITY BY SUSTAINABILITY DIMENSION

Finally, it is also possible to asses the level of maturity of the SC (LMSC) attending to the level of maturity reached by each dimension of sustainability $\left(\mathrm{LMSD}_{\mathrm{j}}\right)$ in an aggregated and averaged way. This is computed using Equation 3 . Attending to the data suggested in this simulation study the level of maturity is 3.18 which mean that the SC is in the level of maturity 3 in terms of sustainability.

This approach makes also possible to perform a comparative analysis between the levels of maturity of each dimension of sustainability and the level of maturity of the SC. In this study it is possible to see that besides the higher level of maturity verified in the environmental dimension of sustainability (Level 4) the SC has a maturity level of sustainability of 3 this is because of the lower level of maturity verified in the social dimension.

\section{CONCLUSIONS}

The proposal of MM is considered an interesting and useful topic that makes possible to assess the development' state of a diversified kind of entities (processes, systems, practices). In this paper a MM for assessing the sustainability of supply chains is proposed considering different levels of analysis and aggregation: by sustainability practices, sustainability dimension and SC. This approach makes possible to reach a deeply analysis of the sustainability behavior of SC and gives insights to decision makers on the practices and dimensions of sustainability where they are better and worst performers. A SC could reach a good level of maturity in terms of sustainability (i.e. level 4 of maturity) but it could hide a low level of maturity in terms of social behavior. With the approach suggested in this paper a more deeply analysis of the sustainability' behavior of SCs could be 
performed supporting strategies and policies of continuous improvement. This approach makes also possible to perform a comparative analysis between the levels of maturity of each dimension of sustainability and the level of maturity of different SCs.

\section{ACKNOWLEDGMENT}

This research is funded by Fundação para a Ciência e Tecnologia (UID/EMS/00667/2013) and FEDER/COMPETE (grant UID/ECO/04007/2013).

\section{REFERENCES}

[1] R. Wendler, "The maturity of maturity model research: A systematic mapping study" in Information and Software Technology, vol. 54, pp 1317-1339, 2012.

[2] C. A. Pigosso, H. Rozenfeld, and T. C. McAloone, "Ecodesign maturity model: a management framework to support ecodesign implementation into manufacturing companies”, Journal of Cleaner Production, vol. 59, pp. $160-173,2013$

[3] M. Ammini, M. and C. Bienstock, "Corporate sustainability: an integrative definition and framework to evaluate corporate practice and guide academic research”, Journal of Cleaner Production, vol. 76, pp. 12-19, 2014.

[4] M. J. Meixell and P. Luoma, "Stakeholder pressure in sustainable supply chain management", International Journal of Physical Distribution and Logistics Management, vol. 45, pp. 69 - 89, 2015.

[5] K. McCormack, M. B. Ladeira, and M. P. V. Oliveira, "Supply chain maturity and performance in Brazil”, Supply Chain Management: An International Journal, vol 13, pp. 272-282, 2008

[6] M. Mani, K. Lyons, and R. Sriam, "Towards the development of a sustainability manufacturing maturity model”, Proceedings from the IMS2010 Summer School on Sustainable Manufacturing, Zurich, Switzerland, pp. 311-319, 2010.

[7] F. Tonelli, S. Evans, S. and P. Taticchi, "Industrial Sustainability: challenges, perspectives, actions”, International Journal of Business Innovation Research, vol. 7 No. 2, pp. 143-163, 2013.

[8] S. Gold, S. Seuring, S. and P. Beske, "Sustainable supply chain management and interorganizational resources: a literature review”, Corporate Social Responsibility and Environmental Management, vol. 17, pp. 230-245, 2010.

[9] C. R. Carter, e P. L. Easton, "Sustainable supply chain management: evolution and future directions", International Journal of Physical Distribution and Logistics Management, vol. 41, pp. 46-62, 2011.

[10] P. Taticchi, F. Tonelli, and R. Pasqualino, "Performance measurement of sustainable supply chains”, International Journal of Productivity and Performance Management, vol. 62, pp. 782-804, 2013.

[11] H. Reefke,, M. D. Ahmed, and David Sundaram, "Sustainable Supply Chain Management-Decision Making and Support: The SSCM Maturity Model and System”, in Global Business Review, vol. 15, pp. 112, 2014

[12] C. Neuhauser, "A maturity model: does it provide a path for online course design?”, The Journal of Interactive Online Learning, Vol 3 No. 1, pp. 1-17, 2004.

[13] G. Klimko, "Knowledge management and maturity models: building common understanding", Proceedings of the Second European Conference on Knowledge Management, Slovenia, pp. 269-278, 2001.

[14] M. Röglinger, J. Pöppelbuß, and J. Becker, "Maturity models in business process management", Business Process Management Journal, vol. 18, pp. 328 - 346, 2012.

[15] C. C. Buckley, "Delphi technique supplies the classic result?” Australian Library Journal, vol. 43, pp. 158-216, 1994

[16] A.P.C., Chan, E. H. K, Yung, P. T. I. Lam, C. M., Tam, and S. O. Cheung, "Application of Delphi method in selection of procurement systems for construction” Construction Management and Economics, vol. 19, pp. 699-718, 2001. 